\title{
Effect of selection for fasting tolerance on feed intake, growth and feed efficiency in the European sea bass Dicentrarchus labrax ${ }^{\star}$
}

\author{
Sophie Daulé ${ }^{a, b}$, Marc Vandeputte ${ }^{a, b, *}$, Alain Vergnet ${ }^{a}$, Bruno Guinand ${ }^{c, d}$, Laure Grima ${ }^{a, b}$, \\ Béatrice Chatain $^{a}$
}

\author{
a Ifremer, UMR110 INTREPID, Chemin de Maguelone, F-34250 Palavas-les-Flots, France \\ b INRA, UMR1313 GABI, F-78350 Jouy-en-Josas, France \\ ${ }^{c}$ UMR CNRS 5554 ISE-M, F-34000, Montpellier, France \\ d Université Montpellier 2, F-34000, Montpellier, France \\ *: Corresponding author : Marc Vandeputte, tel.: + 33467130407 ; email address : marc.vandeputte@jouy.inra.fr
}

\begin{abstract}
:
Feed efficiency is a major goal for aquaculture sustainability, and selecting fish to genetically enhance this trait would be highly valuable. However, no selective breeding program specifically targeted to feed efficiency exists for farmed fish, mostly because of the difficulty of measuring individual feed intake. However, a negative phenotypic correlation between feed efficiency and weight loss at fasting has been previously demonstrated in sea bass submitted to feed deprivation (FD). We mated sea bass parents selected for their high $\left(\mathrm{FD}^{+}\right)$or low $\left(\mathrm{FD}^{-}\right)$weight loss at fasting to produce $\mathrm{FD}^{+}$and $\mathrm{FD}^{-}$progeny, which were reared in a single tank to avoid common environmental effects. At 8 months of age, 1200 of those fish were submitted to three alternating periods of fasting ( 3 weeks) and re-feeding ( 3 weeks). Individuals were weighed at the end of each feeding and fasting period. Their line of origin was identified by genotyping of 12 microsatellite markers, resulting in 1130 unambiguously assigned fish (484 FD', $686 \mathrm{FD}^{+}$). FD offspring lost significantly less weight than $\mathrm{FD}^{+}$offspring in this feed deprivation trial. After that, the feed efficiency of eight groups of $50 \mathrm{FD}^{+}$fish and eight groups of $50 \mathrm{FD}^{-}$fish was evaluated in four successive 20-day periods. At the end of the fourth period, 10 fish per tank were sacrificed to evaluate their carcass yield. The FD $^{-}$fish had a better overall growth and were fatter, and $\mathrm{FD}^{+}$fish had a better carcass yield. A better feed efficiency was expected for the $\mathrm{FD}^{-}$fish, but differences between the two groups for this trait, measured either with feed efficiency ratio or with residual feed intake, were not consistently significant. Although the two lines were clearly divergent for several traits, demonstration of feed efficiency differences between the FD ${ }^{+}$and the $\mathrm{FD}^{-}$lines was not consistently observed in sea bass. A second generation of selection may allow further divergence in the lines and reveal differences in feed efficiency.
\end{abstract}

\section{Highlights}

We performed divergent selection of sea bass for fasting tolerance. Selection response was observed for fasting tolerance (half of expected response). Correlated response on growth and fat content was observed. Correlated response on feed efficiency was inconsistent.

Keywords: European sea bass ; Dicentrarchus labrax ; Selective breeding ; Feed efficiency ; Fasting tolerance

\footnotetext{
* Paper presented at the International Symposium on Genetics in Aquaculture XI, Auburn, AL, USA, June 24-30, 2012.
} 


\section{Introduction}

Feed efficiency is a very important issue in aquaculture, particularly for carnivorous species, which are partially fed with fish meal and fish oil. This dependency upon marine capture fisheries is a problem because of the lack of availability and the increasing price of fish meal and oil (Tacon and Metian, 2008). Pressure on natural resources and production costs of fish farming could be diminished by enhancing feed efficiency. A better feed efficiency would also reduce waste production and the associated environmental impact (Talbot and Hole, 1994).

Feed efficiency, the capacity to generate biomass from food consumed, is expressed through two indices. The Feed Efficiency Ratio (FER) is the number of growth units per unit of quantity eaten. The Residual Feed Intake (RFI) is the difference between the observed feed intake and a theoretical feed intake accounting for production level. FER have the advantage to be a simple index with direct economic impact, but it varies with growth and age, whereas RFI is not influenced by growth.

Feed efficiency of fish productions has already been increased by enhancing rearing and feeding processes. Indeed, in fish, feed efficiency depends on physical factors, like temperature (Buentello et al., 2000 ; Imsland et al., 2006 ; Handeland et al., 2008 ; Wang et al., 2009), photoperiod (Biswas et al., 2005), oxygen concentration (Buentello et al., 2000), and nutritional factors, like food digestibility (Aksnes et al., 1997). Since the 1980s, progress in feed formulation and in feed processing technologies has enabled a significant increase in feed efficiency (Bureau and Hua, 2010), and selective breeding could lead to further improvements.

Indeed, selection based on feed efficiency is a usual practice in poultry breeding (Emmerson, 1997). In cattle, feed efficiency has been studied in research, and future selection programs based on this criterion are possible (Crews, 2005). In fish, feed efficiency has a significant genetic variation. In Atlantic salmon, the full-sib family effect has been shown to explain 31 to $77 \%$ of feed efficiency variation (Thodesen et al., 2001; Kolstad et al, 2004), and Grima et al. (2008) showed a strong genetic effect on residual feed intake in rainbow trout. Conversely, a heritability of $0.03 \pm 0.10$ has been found for feed efficiency in rainbow trout (Kinghorn,(1983). Nevertheless, selection programs directly based on this criterion are not implemented, primarily due to difficulties accurately measuring feed efficiency on individual fish. Estimating individual feed efficiency requires the measurement of individual growth and individual feed intake, which implies rearing fish individually (Nikki et al., 2004; Martins et al., 2006) or estimating feed intake on X-ray images of fish fed with labelled food (Talbot et Higgins, 1983). The disadvantage of individual rearing is that it does not consider social interactions. According to Silverstein (2006), feed efficiency measured on individually housed fish is informative concerning the efficiency of the group, but gives better performances than measurement in groups, probably because of the energetic cost of social interactions. For Martins et al. (2008), behaviour variability explains part of the variability of feed efficiency. Consequently, it is necessary to measure feed efficiency on group-reared fishes in order to reveal the maximum of feed efficiency variability. Selection to diminish feed intake using the X-ray method was shown to be promising in rainbow trout (Kause et al., 2006), so, we can suppose that a breeding program based on the X-ray method could also enhance feed efficiency. However, this technique has a low repeatability (Kause et al, 2006), could be difficult to use for recently domesticated species as it implies frequent handling of the fish (Grima, 2010), and would be difficult to apply in a routine breeding program. Consequently, our goal is to set up a selection trial based on an easily measurable indirect criterion, highly correlated with feed efficiency.

The major trait selected for in fish breeding is rapid growth, but it gives divergent results on feed efficiency. In Atlantic salmon (Thodesen et al., 1999) and in Coho salmon (Neely et al. 2008), feed efficiency was better in the selected line whereas in brown trout (Mambrini et al., 2004, and Sanchez et al., 2001), the selected line did not differ from the control line for feed efficiency. In red sea bream Ogata et al. (2002) reported that feed efficiency had decreased after selection for rapid growth. So, selection for growth cannot be considered a generally reliable means to improve feed efficiency. 
Recently, a significant negative correlation of feed efficiency with weight loss during feed deprivation (FD), and with weight gain during re-feeding (RF) was demonstrated in rainbow trout (Grima et al., 2008), and in sea bass (Grima et al., 2010a). It was predicted by Grima et al. (2010b), that an individual selection based on FD performances with a selection intensity of one would lead to $0.55 \%$ feed saving per generation in sea bass.

Fat metabolism and retention needs to be considered in developing breeding programs for feed efficiency, as fat retention differences could explain some of the differences in feed efficiency. Indeed, a negative correlation has been found between feed efficiency and whole body lipid content in European whitefish (Quinton et al., 2007) and in Coho salmon (Neely et al., 2008). It is supposed that a preferential use of lipid for energetic requirements, keeping protein for growth, is responsible of the better feed efficiency (Neely et al., 2008). However, Grima et al. (2010b) found a positive correlation between feed efficiency and muscle fat content in sea bass.

In the present experiment, we performed a selection trial based on weight loss during feed deprivation in sea bass, expecting that offspring of FD $^{-}$parents (losing less at feed deprivation) would have a better feed efficiency than offspring of $\mathrm{FD}^{+}$parents (losing more weight at feed deprivation). We first tested the selection response on the trait selected (weight loss at feed deprivation), then we measured feed efficiency in $\mathrm{FD}^{-}$and $\mathrm{FD}^{+}$offspring. We also examined whether fat content differed between the two lines.

\section{Materials and methods}

\subsection{Broodstock selection}

The parental broodstock was selected from the offspring of a full factorial factorial mating involving 41 sires and eight dams collected from the wild in the West Mediterranean (Grima et al., 2010b). Parents were chosen for their growth performance during two consecutive feed deprivation (FD) periods (Grima et al., 2010b). The trait selected was the average TGC (Thermal Growth Coefficient) from the two periods, corrected by the initial weight and the initial TGC (FDcorr in Grima et al., 2010a). FDcorr data from 1920 individual sea bass were available, and we selected 5 dams and 20 sires at both ends of the distribution. The average selection differential was +1.49 phenotypic standard deviations $\left(\sigma_{\mathrm{P}}\right)$ for FDcorr in the five FD- selected dams, $+2.25 \sigma_{\mathrm{P}}$ in the $20 \mathrm{FD}^{-}$selected sires, $-1.81 \sigma_{\mathrm{P}}$ in the five $\mathrm{FD}^{+}$selected dams and $-1.74 \sigma_{\mathrm{P}}$ in the $20 \mathrm{FD}^{+}$selected sires. Sperm from the selected males was collected and cyopreserved in $250 \mathrm{ml}$ straws according to the method described in Fauvel et al. (1998). Offspring were produced mating five $\mathrm{FD}^{+}$dams with twenty $\mathrm{FD}^{+}$sires, and five $\mathrm{FD}^{-}$dams with twenty $\mathrm{FD}^{-}$sires, in order to obtain around $600 \mathrm{FD}^{+}$fish from 100 full-sib families and $600 \mathrm{FD}^{-}$fish from 100 full-sib families. After hormonal induction of ovulation $(10 \mu \mathrm{g} / \mathrm{kg}$ luteinizing hormone-releasing hormone, Sigma, D-TRP6LHRH), eggs were obtained by hand stripping of the $5 \mathrm{FD}^{+}$dams and $5 \mathrm{FD}^{-}$dams. Twenty aliquots of $10 \mathrm{ml}$ eggs each were collected from each dam. Each aliquot was individually fertilized with thawed sperm from a single sire of the same type, so that all FD' dams were fertilized by all FD- sires, and all $\mathrm{FD}^{+}$dams were fertilized by all FD ${ }^{+}$sires. Five minutes after fertilization, eggs were pooled by dam for incubation. At 48 hours post-fertilization, $8 \mathrm{ml}$ of viable (floating) eggs were collected from each incubation tank and mixed in a single $0.5 \mathrm{~m}^{3}$ tank containing all families. Standard rearing condition were used, except for early temperature which gradually increased from $13.5^{\circ} \mathrm{C}$ to $18^{\circ} \mathrm{C}$ over the first 12 days, and further increased to $25^{\circ} \mathrm{C}$ at 49 days post-fertilization (dpf), coming back to natural temperature $\left(20-22^{\circ} \mathrm{C}\right)$ at $112 \mathrm{dpf}$.

\subsection{Initial growing period and parental assignment}

At $126 \mathrm{dpf}$, fish were transferred to a $1.5 \mathrm{~m}^{3}$ fiberglass tank. At $227 \mathrm{dpf}, 1200$ randomly chosen fish were individually tagged with a Passive Integrated Transponder (AEG-id, Germany), and were measured for initial body weight and length, and transferred to a $5 \mathrm{~m}^{3}$ fiberglass tank. Fish were 
anesthetized with 2-phenoxy-ethanol $(0.4 \mathrm{ml} / \mathrm{l})$ during tagging and biometry. Feeding was stopped $24 \mathrm{~h}$ before the biometry and fish were immediately re-fed after the measurement. A piece of fin from each fish was collected for DNA extraction for parentage assignment. Twelve microsatellite markers were used for the genotyping by LABOGENA (Jouy en Josas, France). The software VITASSIGN (Vandeputte et al, 2006) was used to perform parentage assignment based on the multilocus microsatellite genotype of the fish, with two allelic mismatches tolerated, resulting in $94.2 \%$ of the fish being assigned to a single parental pair. Among the 1130 assigned offspring, there were $484 \mathrm{FD}^{-}$fish belonging to 77 full-sib families, and $646 \mathrm{FD}^{+}$fish, belonging to 86 full-sib families.

\subsection{Experimental phase 1: Alternance of feed deprivation and re-feeding}

In the $5 \mathrm{~m}^{3}$ fibreglass tank, we first measured the initial growth over a six weeks period, from 227 to $276 \mathrm{dpf}$ (BG, see Fig.1). The initial six week feeding was followed by alternating periods of feed deprivation for three weeks $\left(F D_{1}, F_{2}, F_{3}\right.$, see Fig. 1) and four $\left(R F_{1}\right)$ or three $\left(R_{2}, R_{3}\right)$ weeks of re-feeding (see Fig.1). At the end of each period, all fish were individually identified by their PIT-tag and measured for weight (nearest $0.1 \mathrm{~g}$ ) and total length (nearest $\mathrm{mm}$ ). During feeding periods, fish were fed ad libitum using a self-feeder with a standard commercial diet (Neogrower, Le Gouessant, France), containing $45 \%$ protein and $17 \%$ lipid.

\subsection{Experimental phase 2: Feed efficiency measurement (FEM)}

Among fishes present at the end of the third RF phase, we randomly chose $400 \mathrm{FD}^{+}$and $400 \mathrm{FD}^{-}$ offspring with unambiguous parentage identification to constitute eight batches of 50 fish from each selected line. They were transferred in a room with sixteen $0.7 \mathrm{~m}^{3}$ fiberglass tanks at $428 \mathrm{dpf}$. FD and FD' groups were assigned to alternating tank placements to homogenize potential environmental perturbations. Fish were fed at libitum five days a week, once a day at 9:00 with the same feed as before. Food was distributed in small batches (between 3 and $5 \mathrm{~g}$ ) with manually controlled feeders until the first pellets went through the fecal trap outlet at the tank bottom. After the feeding session, uneaten pellets were collected in the fecal trap and counted, according to the Helland et al. (1996) method. At the beginning of each week, hoppers were filled with $1000 \mathrm{~g}$ of pellets. Residual pellets were weighted at each end of week. Four three weeks feeding periods were conducted and the corresponding feed efficiencies were determined, FEM, 428 to 448 dpf; FEM 449 to $469 \mathrm{dpf}, \mathrm{FEM}_{3} 470$ to $490 \mathrm{dpf}$ and $\mathrm{FEM}_{4}, 491$ to $511 \mathrm{dpf}$. At the end of each cycle, body weight, body length and muscle fat content (Distell Fish Fatmeter, FM 692) were measured on each individually tagged fish. At $511 \mathrm{dpf}$, ten fish per tank were randomly chosen to be slaughtered and eviscerated. Liver, perivisceral fat, digestive tract and eviscerated carcass were weighed to the nearest $0.01 \mathrm{~g}$.

\subsection{Processing raw data}

Growth was determined through two calculations. The Body Weight Gain (BWG) is the difference (in $\mathrm{g}$ ) between two successive measurements of weight. We also expressed the growth rate with the Thermal Growth Coefficient (TGC), a standardized index which is not affected by body weight, time interval, or water temperature (Iwama and Tautz, 1981) :

$$
\mathrm{TGC}=100^{*}\left(\text { final } \mathrm{BW}^{1 / 3}-\text { initial } \mathrm{BW}^{1 / 3}\right) /(\Sigma \text { Temp})
$$

where BW is the body weight $(\mathrm{g})$ in grams and $\Sigma$ Temp is the sum of average daily temperatures $\left({ }^{\circ} \mathrm{C}\right)$. TGC was calculated for all periods, a mean TGC was calculated for the three FD periods and the three RF periods, and an overall TGC was calculated as the TGC between 227 and $428 \mathrm{dpf}$.

The Fulton coefficient of condition, was calculated as $K=100^{*} \mathrm{BW} / \mathrm{BL}^{3}$, with $\mathrm{BL}$ the total body length $(\mathrm{cm})$ Fat content $(\mathrm{Fc}$, in \%) was the mean of two Fatmeter measurements (Distell Fish Fatmeter, FM 692) on the left dorsal muscle. Liver, perivisceral fat, digestive tract and eviscerated carcass weight obtained at the final measurement were used to calculate hepatosomatic index $\left(\mathrm{HSI}=100^{*}\right.$ liver weight/BW $)$, digestive tract index $\left(\mathrm{DTI}=100^{*}\right.$ digestive tract weight $\left./ \mathrm{BW}\right)$, pe- 
rivisceral fat index $\left(\mathrm{VFI}=100^{*}\right.$ perivisceral fat weight $\left./ \mathrm{BW}\right)$, and carcass yield $(\mathrm{CarcY}=$ $100^{*}$ eviscerated carcass weight/ BW).

For each week of a FEM period, feed intake $(\mathrm{FI})$ of each batch was calculated as $\mathrm{FI}(\mathrm{g})=($ initial quantity of pellets in the hopper(g) - residual pellets $(\mathrm{g})$ - number of uneaten pellets * weight of one pellet(g)). Mean Feed Intake per fish of the same batch (MFI) was calculated for each FEM period as $\mathrm{FI}(\mathrm{g})$ / number of fish in the batch. Because some fish died during the experiment, we had to correct values of MFI and mean body weight gain (BWG) during some FEM periods. Mean BWG was calculated taking into account only fish that were alive at the end of the cycle. MFI was corrected by subtracting from $\mathrm{FI}$ the estimated consumption of each dead fish until the day before its death. For this, we hypothesized that each fish in a given batch ate a proportion of the feed distributed equal to its proportion in the batch biomass, and that the amount of food distributed was the same each day of the week.

Feed efficiency is generally expressed through two indices, FER (Feed Efficiency Ratio) and RFI (Residual Feed Intake). FER was calculated as FER= BWG (g) / MFI (g). RFI is the difference between the MFI measured and the expected MFI (MFlexp), which is the result of a prediction model based on energy balance, as proposed by Crews (2005):

$$
\text { MFlexp } p_{i}=b_{0}+b_{1} \cdot M B W G_{i}+b_{2} \cdot M M W_{i} .
$$

Where MFlexp is the expected mean feed intake of batch $i, b_{0}$ is the regression intercept, $b_{1}$ is the partial regression coefficient of MFI on mean body weight gain in batch $i\left(M B W G_{i}\right), b_{2}$ is the partial regression coefficient of mean $\mathrm{FI}$ on the mean of metabolic body weight in batch $\mathrm{i}\left(\mathrm{MMW}_{\mathrm{i}}\right)$.

The metabolic weight (MW) of each fish was calculated as the weight estimated at the midpoint of the cycle, raised to the power 0.8 , and MMW was the average of metabolic weights in a tank. We calculated the MW of each fish, and the mean MMW for each batch. The model coefficients $b_{0}, b_{1}$, and $b_{2}$ were estimated at each FEM period using a multiple regression model in SAS 9.2 (The SAS Institute, Cary, NC) .

\subsection{Statistical analyses}

All statistical analyses were done performing anova and ancova with SAS-GLM, and in all cases we focalized on the differences between $\mathrm{FD}^{+}$and $\mathrm{FD}^{-}$fish. For growing and alternate feed deprivation and re-feeding periods, BW and TGC were analysed considering individual fish as the experimental unit.

In the experimental phase 1 , in order to assess the effect of selection line on TGC, BW, and K, we used following mixed model:

$$
\mathrm{Y}_{i j k l}=\mu+\text { line }_{i}+\operatorname{sire}_{j}\left(\text { line }_{i}\right)+\operatorname{dam}_{k}\left(\text { line }_{i}\right)+\mathrm{e}_{i j k l}\left\{\text { anova }_{1}\right\}
$$

Where $Y_{i j k l}$ is the individual fish performance, $\mu$ is the population mean, line is the fixed effect of the line $\left(i=\mathrm{FD}^{+} ; \mathrm{FD}^{-}\right)$, sire $\left(\right.$line $\left._{i}\right)$ and $\operatorname{dam}_{k}\left(\mathrm{line}_{i}\right)$ are the random effects of each parent within each line, and $e_{i j k l}$ is the random residual.

Because TGCs in FD and RF periods depends on individual body weight and initial growth, and hence the selection criterion was the TGC in feed deprivation periods corrected by $\mathrm{BW}_{0}$ and $\mathrm{TGC}_{0}$ as calculated in Grima et al. (2010a), we also tested the following model on TGC $\mathrm{FD}_{1}, \mathrm{TGC}_{\mathrm{RF} 1}$, $\mathrm{TGC}_{\mathrm{FD} 2}, \mathrm{TGC}_{\mathrm{RF} 2}, \mathrm{TGC}_{\mathrm{FD} 3}$, and $\mathrm{TGC}_{\mathrm{RF} 3}$ :

$$
\mathrm{Y}_{i j k l}=\mathrm{a} \cdot B \mathrm{BW}_{0 \mathrm{ijkl}}+\mathrm{b} \cdot \mathrm{TGC}_{0 \mathrm{ijkl}}+\text { line }_{i}+\text { sire }_{j}\left(\text { line }_{i}\right)+\operatorname{dam}_{k}\left(\text { line }_{i}\right)+\mathrm{e}_{i j k l}\left\{\text { ancova }_{1}\right\}
$$

Where $Y_{i j k l}$ is the individual fish performance, $a$ is the partial regression coefficient of $Y_{i j k l}$ on $B W_{0 j \mathrm{jkl}}$, the initial body weight at $227 \mathrm{dpf}, \mathrm{b}$ is the partial regression coefficient of $Y_{\mathrm{ijkl}}$ on $\mathrm{TGC}_{0 \mathrm{ijkl}}$, the ther- 
mal growth coefficient calculated during the initial growing phase, line $e_{i}$ is the fixed effect of the line $\left(i=\mathrm{FD}^{+} ; \mathrm{FD}^{-}\right)$, sire ${ }_{j}\left(\right.$ line $\left._{i}\right)$ and dam $_{k}\left(\right.$ line $\left._{i}\right)$ are the random effect of each parent inside each line, and $\mathrm{e}_{i j k l}$ is the random residual.

However, in some periods, the regression of TGC with $\mathrm{P}_{0}$ had significantly different slopes in $\mathrm{FD}^{+}$ and FD $^{-}$offspring - and ancova ${ }_{1}$ could therefore not be used - whereas regressions of TGC on $\mathrm{TGC}_{0}$ were not significantly different in $\mathrm{FD}^{+}$and $\mathrm{FD}^{-}$lines. Therefore, we used the following model, with correction only for $\mathrm{TGC}_{0}$, as follows:

$$
\mathrm{Y}_{i j k l}=\mathrm{a} \cdot \mathrm{TGC}_{0 \mathrm{ijkl}}+\text { line }_{i}+\text { sire }_{j}\left(\text { line }_{i}\right)+\operatorname{dam}_{k}\left(\text { line }_{\mathrm{i}}\right)+\mathrm{e}_{i j k l}\left\{\text { ancova }_{2}\right\}
$$

Where $Y_{i j k l}$ is the individual fish performance(BW, TGC or K), a is the partial regression coefficient of $Y_{\mathrm{ijkl}}$ on $\mathrm{TGC}_{0 \mathrm{jikl}}$, the thermal growth coefficient calculated during the initial growing phase, line $e_{i}$ is the fixed effect of the line $\left(i=\mathrm{FD}^{+} ; \mathrm{FD}^{-}\right)$, sire ${ }_{j}\left(\right.$ line $\left._{i}\right)$ and dam $_{k}\left(\right.$ line $\left._{i}\right)$ are the random effects of each parent within each line, and $\mathrm{e}_{i j k l}$ is the random residual.

For FEM periods, FER and RFI were treated considering tank at the experimental unit, whereas body size and conformation measurements were treated considering fish as experimental unit. FER and RFI were analysed with the following model:

$$
Y_{i j}=\mu+\text { line }_{i}+e_{i j}\left\{\text { anova }_{2}\right\}
$$

Where $Y_{i j}$ is the tank performance, $\mu$ is the population mean, line $e_{i}$ is the fixed effect of the line (i= $\left.\mathrm{FD}^{+} ; \mathrm{FD}^{-}\right)$, and $\mathrm{e}_{i j}$ is the random residual.

Body weight, BWG, TGC, K, and Fc at 428, 448, 469, 490, $511 \mathrm{dpf}$, and HSI, DTI, VFI, and carc. $\mathrm{Y}$. at $511 \mathrm{dpf}$ were tested with the following model:

$$
\mathrm{Y}_{i j k}=\mu+\operatorname{line}_{i}+\operatorname{tank}_{j}\left(\text { line }_{i}\right)+\mathrm{e}_{i j k}\left\{\text { anova }_{3}\right\}
$$

Where $Y_{i j k}$ is the individual performance of fish $k, \mu$ is the population mean, line $e_{i}$ is the fixed effect of the line ( $\left.i=F D^{+} ; F D^{-}\right)$, tank ${ }_{j}\left(\right.$ line $\left._{i}\right)$ is the random effect of tank $j$ nested within line $e_{i}$, and $e_{i j k}$ is the random residual.

At $428 \mathrm{dpf}$, when fish were transferred into separate tanks, anova ${ }_{3}$ permitted to check the homogeneity of batches. In order to test the parental effect, TGC, K, and Fc at 428 were also tested with anova $_{1}$ at $428 \mathrm{dpf}$.

Differences between lines were evaluated by $F$ tests on the line effect, and when appropriate the nested random effects (sire and dam in the experimental phase 1, tank in the experimental phase 2 ) were used as the residual for the $F$ tests.

The theoretical response to selection for fasting tolerance, expressed in phenotypic standard deviation $\left(\sigma_{P}\right)$ units was calculated as $\Delta G=S D{ }^{*} h^{2}$, with $S D$, the selection differential of the parents for the TGC during feed deprivation, corrected for the effects of initial body weight and growth, and $\mathrm{h}^{2}$ the heritability of this trait. It was compared to the observed selection response.

\section{Results}

\subsection{Weight changes during feed deprivation and refeeding}

During this first experimental phase, the mean BW was always higher in FD- fish (Figure 1, Table 1), where it was $3.8 \%$ higher than in $\mathrm{FD}^{+}$fish at $227 \mathrm{dpf}$, and $9.1 \%$ higher at $408 \mathrm{dpf}$. However, this 
difference was never significant according to anova ${ }_{1}(P>0.2)$, meaning that the line effect was not demonstrated.

TGC was also always higher in FD fish at all periods (Fig.1, Table 2), and this difference was significant only during $\mathrm{FD}_{1}, \mathrm{RF}_{2}$ and $\mathrm{FD}_{3}$, as well as on the overall means of $F D$ and RF periods (ano$v \mathrm{a}_{1}$ ). The line effect was more difficult to understand. We could not use correction by initial body weight and $\mathrm{TGC}_{0}\left(\right.$ ancova $\left._{1}\right)$ for $\mathrm{TGC}_{\mathrm{FD} 2}, \mathrm{TGC}_{\mathrm{RF} 2}$, and for the mean $\mathrm{TGC}_{\mathrm{RF}}$, because of heterogeneity of slopes for regression on $\mathrm{P}_{0}$ between $\mathrm{FD}^{-}$and $\mathrm{FD}^{+}$fish. Therefore, we used correction only for $\mathrm{TGC}_{0}\left(\right.$ ancova $\left._{2}\right)$, which gave results very close to ancova ${ }_{1}$ when both could be performed. Models gave convergent results showing that TGC during $\mathrm{FD}_{1}$ and $\mathrm{FD}_{3}$, as well as the mean $\mathrm{TGC}$ of the three FD periods, was significantly higher in the FD- line. The fact that anova and ancova models gave similar results proved that the significant smaller weight loss of the $\mathrm{FD}^{-}$line in $\mathrm{FD}_{1}$ and $\mathrm{FD}_{3}$ (and in the mean of all three FD periods) was not a consequence of a difference in overall growth capacity but of a specific tolerance to fasting. The difference of TGC between lines was clearly not significant during $\mathrm{RF}_{1}, \mathrm{FD}_{2}$, and $\mathrm{RF}_{3}$. The existence of differences between lines for $T G C_{\mathrm{RF} 2}$ and mean TGC of the three RF periods was ambiguous as anova and ancova models gave divergent results. The fact that differences were significant with anova models but not with ancova models showed that the higher TGC of the FD- line in RF periods was a consequence of a higher overall growth capacity, but not of a specific aptitude for compensatory growth. In summary, FD $^{-}$line fish had resistance to fasting but neither line had a specific capacity for re-feeding growth. Nevertheless, FD $^{-}$always had a higher TGC, and this difference was significant in several periods according to anova ${ }_{1}$, ancova ${ }_{1}$, and ancova . $_{2}$

The mean coefficient of condition of $\mathrm{FD}^{-}$fish was also always higher than that of $\mathrm{FD}^{+}$fish, and differences were significant (anova $0: P<0.0001$ ). According to anova ${ }_{1}$, the difference between lines was significant (at 276 and $324 \mathrm{dpf}$ ) or close to significance (at $366 \mathrm{dpf}, P=0.08$ ) after RF periods only (Table 1).

For calculating the expected response to selection for $\mathrm{TGC}_{\mathrm{FD}}$, the selection differential was $3.645 \sigma_{P}$ and $h^{2}$ was 0.23 (Grima et al., 2010b), so $\Delta G$ was expected to be $0.84 \sigma_{p}$. The residual standard deviation of offspring mean TGC during feed deprivation, corrected for initial growth and body weight in ancova ${ }_{1}$, was 0.0036 , so theoretical response to selection was 0.0030 in TGC units. The observed difference of mean FD TGC between the two groups was 0.0016 , half of the expected response

\subsection{Feed efficiency measurement}

During $\mathrm{FEM}_{1}$, feed intake was low (between 2 and $7 \mathrm{~g}$ per fish, Fig. 2) and fish lost weight (Table 3 ), thirteen fish died ( 5 in $\mathrm{FD}^{-}$and 8 in $\mathrm{FD}^{+}$), because of nitrogen supersaturation in the water, due to an air leakage in a pump - which was fixed. It is worth noting that in all tanks, some fish grew and some fish lost weight. During the first week of $\mathrm{FEM}_{2}$, all fish in a FD ${ }^{+}$tank died because of technical problem, and were replaced at the beginning of the second week by other $\mathrm{FD}^{+}$fish. They were not considered for $\mathrm{FEM}_{2}$ statistics. During $\mathrm{FEM}_{2}$, ten more fish died, most likely because of bacterial infections on supersaturation lesions. Lesions have been progressively cured by an antibiotic treatment mixed with the feed (oxytetracyclin, $10 \mathrm{~g} / \mathrm{kg}$, two weeks). The mean FI during $\mathrm{FEM}_{2}$ was between 5 and $35 \mathrm{~g}$ per fish and the mean growth of each tank was positive, but some fish continued losing weight. Only one fish died during $\mathrm{FEM}_{3}$ and the tank replaced in $\mathrm{FEM}_{2}$ had results comparable to others tanks. No fish lost weight during $\mathrm{FEM}_{3}$ and $\mathrm{FEM}_{4}$, and the mean feed intake (MFI) per fish was between 20 and $45 \mathrm{~g}$.

In all FEM cycles, MFI, BWG and TGC were higher in the $\mathrm{FD}^{-}$line (Fig. 2). MFI and BWG were significantly different between $\mathrm{FD}^{+}$fish and $F D^{-}$fish during $F E M_{2}, F E M_{3}$, and $F E M_{4}$, while TGC was significantly different between $\mathrm{FD}^{+}$and $\mathrm{FD}^{-}$fish only during $\mathrm{FEM}_{2}$ and $\mathrm{FEM}_{3}$. The mean $\mathrm{FER}$ was higher in the FD- line during $\mathrm{FEM}_{2}$ (the difference was close to significance, $P=0.078$ ), but then it was higher in the $\mathrm{FD}^{+}$line during $\mathrm{FEM}_{3}(P<0.01)$, and similar in both lines during $\mathrm{FEM}_{4}(\mathrm{Fig} .2)$. 
Residual Feed Intake was always lower in the $\mathrm{FD}^{+}$line, but these differences were never significant $(0.81>P>0.17$, Fig. 2$)$.

During all FEM periods, BW, K, and Fc were significantly higher in FD- fish, according to anova (Table 3). At $428 \mathrm{dpf}$ (the day of batches constitution), there was no tank effect, meaning that batches were homogenous within the same line. As from $469 \mathrm{dpf}$, tank effect was always significant for BW, K, and Fc. Fat content has also been tested by anova ${ }_{1}$, and the result was not significant $(P=0.85)$, so the line effect was not demonstrated. At $511 \mathrm{dpf}$, hepatosomatic index and perivisceral fat index were higher in $\mathrm{FD}^{-}$fish, whereas carcass yield was higher in $\mathrm{FD}^{+}$fish (Table 3 ). According to anova $_{3}$, these differences were significant for all traits except HSI and DTI.

\section{Discussion}

The parentage of the experimental fish was successfully assessed with microsatellite markers (>94\% unique assignments). This was essential for breeding all fish in the same tank and thus obtaining results with minimal confounding from environmental effects. The second experimental phase, in which feed efficiency was measured, was affected by some experimental problems, but nevertheless yielded valuable results, thanks to the high number of replicate tanks (eight per line).

\subsection{FD and RF performances}

Overall, FD ${ }^{-}$fish grew faster than $\mathrm{FD}^{+}$fish.. However, the low number of dams (five per line) reduced the power of F-tests performed with anova ${ }_{1}$, which may to some extent explain the lack of significance of some differences tested by anova ${ }_{1}$, which was not the case using a simpler model where only line effect and residual were kept, in which case the difference between lines for body weight and growth rate was significant at all times (data not shown). However, such a simplified model only tests for the difference between offspring groups, not taking into account the sampling of parents (Vandeputte et al., 2001).

We proved that there was a specific tolerance to fasting for FD- line, hence the higher TGC of FDline during FD periods. This specific tolerance was an expected effect of the selection performed. We calculated the expected selection response on mean TGC of the three FD periods, corrected by the effect of initial body weight and growth, as it was done for the selection criterion (Grima et al., 2010b). The reason for this correction was to try to define a selection criterion for feed efficiency which would be independent from growth rate, which is easily selected for, but has contrasted effects on feed efficiency (Thodesen et al., 1999; Sanchez et al. 2001; Ogata et al. 2002; Mambrini et al., 2004).

The observed difference of mean FD TGC between the two groups, half of the expected selection response. In the present experiment, like in Grima et al. (2010a,b), TGC measurements were variable between different FD periods, and the difference between $\mathrm{FD}^{-}$and $\mathrm{FD}^{+}$lines was not significant at all periods. Moreover, Grima et al. (2010a) worked on fish which were older and bigger than ours, and consequently had higher maintenance requirements (Luiting, 1999). This higher maintenance requirement may explain the more important loss of weight during a three week FD challenge in Grima et al. (2010a), and thus higher differences between FD and FD ${ }^{+}$parental groups. Furthermore, when a selection is realized, there is a sampling variance which makes that observed values very often differ from theoretical values (Nicholas, 1980).

Fish belonging to the FD- line had also a significantly higher TGC than $\mathrm{FD}^{+}$fish during RF periods. This superiority was not due to a growth capacity specific to re-feeding of the FD- line, but to the overall growth capacity of the FD- line. Theoretically, a line effect inducing specific capacity to refeeding for $\mathrm{FD}^{+}$line was expected, as Dupont-Prinet et al. (2010) showed that there was a negative correlation between BW losses during feed deprivation and BWG during growth compensation in 
sea bass. Despite the trade-off, it was however possible to identify fish combining a good resistance on feed deprivation and a good growth on re-feeding, and conversely, in the parental population (Grima et al., 2010a). Parents for our experiment were exclusively chosen according to the FDcorr criterion, no taking account RF performances, in order to increase the selection differential as much as possible, and because tolerance to feed deprivation seemed to be the best predictor of feed efficiency (Grima et al., 2010b). It was later established that sires and $\mathrm{FD}^{+}$dams were conforming to the trade-off, but that most of the FD- dams we used also had good performances at re-feeding. This fact could explain why the two lines had an equivalent specific tolerance to re-feeding.

\subsection{Feed efficiency measurement}

Considerable differences were observed between the four successive FEM periods, probably due to the lack of an adaptation period and to the supersaturation problem which occurred at the beginning of the trial. However, the investigator taking care of the fish was the same during the whole FEM trial, and the same feeding method was always applied in order to standardize results as much as possible. Then, despite these experimental problems, the observed FER values, at least at the end of the experiment (between 0.68 and 0.85 during $\mathrm{FEM}_{3}$ and $\mathrm{FEM}_{4}$ ) were coherent with other FER estimates in sea bass. A mean FER of 0.67 was calculated between 505 and $679 \mathrm{dpf}$ on sea bass (Grima et al., 2010b). A FER of 0.56 has been estimated for a Greek farm growing European sea-bass from 2 to $350 \mathrm{~g}$ (Aubin et al., 2009).

Weight loss and poor $\mathrm{FI}$ observed during $\mathrm{FEM}_{1}$ could have complementary explanations. Firstly, fish may have suffered from the change in feeding habits, and of the separation into batches which may induce changes in social structure of the groups (Andrew et al., 2004). Secondly, the supersaturation could have prevented fish to eat, and consequently to grow. Consequent to the loss of weight, FER was not calculated for this period. No measurement was significantly different between FD ${ }^{+}$and FD- fish during this first period. Nevertheless, we could have done an adaptation period after the batch separation. As an example, a six week adaptation period was practised in Grima et al. (2010b), and fish did not lose weight during the first FEM period. One possibility would be to consider that only periods 3 and 4 represent "normal" conditions.

Fish which lost weight during $\mathrm{FEM}_{1}$ and $\mathrm{FEM}_{2}$ probably expressed a compensatory growth when re-feeding (Ali et al., 2003). Considering that a fish which gained weight during a FEM period succeeding a FEM period in which it lost weight was in compensatory growth, we estimated that $61 \%$ and $16 \%$ of the fish were in compensatory growth during $\mathrm{FEM}_{2}$ and $\mathrm{FEM}_{3}$ periods, respectively. The proportion of fish which lost weight during $F E M_{1}$ and $F E M_{2}$ was not the same in $F D^{+}$fish and FD $^{-}$fish, as well as the proportion of fish estimated to be in compensatory growth during $\mathrm{FEM}_{2}$ and $\mathrm{FEM}_{3}$. These differences may partly explain FER fluctuations. During $F E M_{2}$, fish in compensatory growth was approximately the same ratio in $\mathrm{FD}^{-}$and $\mathrm{FD}^{+}$fish, but $20 \%$ of $\mathrm{FD}^{+}$fish lost weight whereas only $0.03 \%$ of FD $^{-}$fish lost weight. This important ratio of fish losing weight could explain the lower FER in $\mathrm{FD}^{+}$fish. During $\mathrm{FEM}_{3}$ fish did not lose weight, but there were $0.03 \%$ of $\mathrm{FD}^{-}$fish in compensatory growth and $17 \%$ of $\mathrm{FD}^{+}$fish in compensatory growth including the additional batch, and $20 \%$ no including the additional batch. This important proportion of fish in compensatory growth in $\mathrm{FD}^{+}$fish may explain the significant higher FER observed in $\mathrm{FD}^{+}$batches during $\mathrm{FEM}_{3}$. Nevertheless, the effective raise of feed efficiency during compensatory growth is debatable. It was demonstrated on rainbow trout (Nikki et al., 2004) and on pikeperch (Mattila et al., 2009) that compensatory growth was permitted by increasing feed intake but not feed efficiency, whereas Mambrini et al. (2004) in rainbow trout, and Oh and Noh (2007) in red sea bream observed both a rise of FER and a rise of $\mathrm{FI}$ in fasted fish compared to control fish. During $\mathrm{FEM}_{4}$, no fish lost weight and no fish were in compensatory growth, and FER was similar in $\mathrm{FD}^{-}$and $\mathrm{FD}^{+}$batches. Consequently, it was established that it was no fundamental difference of feed efficiency capacity in $\mathrm{FD}^{-}$or in $\mathrm{FD}^{+}$ fish, but that some perturbation inducted variation on FER batches during some FEM periods.

Despite the absence of statistical significance, the fact that RFI was always positive in FD- $^{-}$batches and negative in $\mathrm{FD}^{+}$batches, even when FER was significantly higher in FD- batches, raised our 
attention. It is commonly accepted that RFI gives a feed efficiency index which is not affected by differences in body weight and growth rate, contrary to FER which decreases with body weight and raises with growth rate (Thodesen et al., 2001 on Atlantic salmon). At each FEM period, BW and TGC were always higher in FD' batches, but there are too many fluctuations to conclude. However, in Grima et al. (2010b), RFI was significantly higher in $\mathrm{FD}^{+}$batches, but it was calculated on seven FEM periods in which FER was higher in FD- fish. In our case, there were too many fluctuations on MFI and BWG to calculate the overall RFI.

Another observation which was realized during all FEM periods was the higher MFI in FD' batches, which can be only partially explained by the higher BW (Handeland et al., 2008). Nevertheless, selection against feed intake was proposed as a way to improve feed efficiency in trout (Kause et al., 2006).

Finally, during the first experimental phase (fasting/refeeding), there were continually environmental perturbations, and FD' line had an overall better growth capacity. The FD' fish also resumed growth and feed intake at a faster rate after the beginning of the FEM period. It may then be that they showed a better adaptation to environmental changes, as seen in some experimental lines of seabass (Millot, 2008) or sole (Mas-Muñoz et al., 2011), but more research is needed to confirm this hypothesis.

\subsection{Body conformation}

The condition index was significantly higher in the FD- line, only after RF periods. The difference between $\mathrm{FD}^{-}$fish and $\mathrm{FD}^{+}$fish was around 0.05 after FD periods and around 0.06 after RF periods. It is probably this higher difference after RF periods which made the line effect significant. A significant difference of condition factor was shown between two lines of coho salmon (selected for rapid growth during 15 generations vs. control) when fed to satiety (Neely et al., 2008). The selected line also expressed a better feed efficiency. In the present experiment, FD' fish had a better growth, a better condition factor, but not a better feed efficiency.

Values obtained for Fc were around $4.5 \%$ at 511 dpf whereas in Grima and al. (2010b), it was around $7.5 \%$ at $679 \mathrm{dpf}$, but there were technical differences in the measurements done. In the present experiment, Fc was significantly higher in FD' fish (like in Grima et al., 2010a) in all measurements realized, but the line effect was not proven. A negative (Quillet et al., 2007 on rainbow trout) and a positive (Grima et al., 2010b on sea bass) correlation between muscle fat content and feed efficiency were shown, whereas in the present experiment, there were no feed efficiency difference between the fat group and lean group. It is possible that differences which were observed in this experiment were only due to BW differences, because of a strong correlation between muscle fat content and body weight on sea bass (Haffray et al., 2007). Unfortunately, it was not possible to correct Fc by body weight because of a difference of slopes between the two lines.

The carcass yield was around $86 \%$ at $511 \mathrm{dpf}$. A better carcass yield (5\% higher) was obtained by Grima et al. (2010b), but this value was obtained after a final feed deprivation period. The difference between $\mathrm{FD}^{-}$fish and $\mathrm{FD}^{+}$fish was clearly established for perivisceral fat index and carcass yield. Unfortunately, testing parental effect was not possible because of the low number of offspring per parent at the final slaughtering. Complementary experiments would be needed to know if this difference was really due to the selection or by the random choice of the sacrificed fish. Nevertheless, it was proved that visceral fat deposition is linked to genetics (Kolstad et al., 2004 on Altantic salmon). Carcass yield is an important quality trait in aquaculture (Haffray et al., 2007), and despite the fact that sea bass is generally commercialized as whole fish, it is not a negligible trait for the future (Chatain, personal communication). Consequently, a selection against feed deprivation resistance which should enhance carcass yield as a correlated response is an interesting perspective. 


\subsection{Conclusion}

To conclude, this selection based on feed deprivation resistance has produced two lines with their specific characters. The FD' line is resistant to fasting, has a better overall significant growth capacity than $\mathrm{FD}^{+}$line, and $\mathrm{FD}^{-}$fish have higher feed intake capacity. The $\mathrm{FD}^{+}$line is sensitive to feed deprivation, and $\mathrm{FD}^{+}$fish are leaner than $\mathrm{FD}^{-}$fish. Some of our results led us to hypothesize that $\mathrm{FD}^{-}$line is less affected by environmental fluctuations, particularly nutritional fluctuations, but more elements are needed to confirm this hypothesis. No significant and stable response to selection was shown on feed efficiency expressed either with FER or with RFI. However, differences observed in this first generation of selection, especially feed intake differences, lead us to expect that feed efficiency differences might be identified in a second generation of selection. Thus, growth, feed efficiency, fat content, and maybe stress response should be measured on more divergent lines.

\section{Acknowledgements}

This research was funded the INRA-lfremer research group on sustainable fish breeding and project REGULBASS from the French National Research Agency. LABOGENA is thanked for efficient genotyping of the fish.

\section{References}

Aksnes, A., Izquierdo, M.S., Robaina, L., Vergara, J.M., Montero, M., 1997. Influence of fish meal quality and feed pellet on growth, feed efficiency and muscle composition in gilthead seabream (Sparus aurata). Aquaculture 153, 251-261.

Ali, M., Nicieza, A., Wootton, R.J., 2003. Compensatory growth in fishes: a response to growth depression. Fish and Fisheries 4, 147-190

Andrew, J.E., Holm, J., Kadri, S., Huntingfo, F.A., 2004. The effect of competition on the feeding efficiency and feed handling behaviour in gilthead sea bream (Sparus aurata L.) held in tanks. Aquaculture 232, 317-331.

Aubin, J., Papatryphon, E., Van Der Werf, H.M.G., Chatzifotis, S., 2009. Assessment of the environmental impact of carnivorous finfish production systems using life cycle assessment. Journal of Cleaner Production 17, 354-361.

Biswas, A.K., Seoka, M., Inoue, Y., Takii, K., Kumai, H., 2005. Photoperiod influences the growth, food intake, feed efficiency and digestibility of red sea bream (Pagrus major). Aquaculture 250, 666- 673.

Buentello, J.A., Galtin, D.M., Neill, W.H., 2000. Effects of water temperature and dissolved oxygen on daily feed consumption, feed utilization and growth of channel catfish (Ictalurus punctatus). Aquaculture 182, 339-352.

Bureau, D.P., Hua, K., 2010. Towards effective nutritional management of waste outputs in aquaculture, with particular reference to salmonid aquaculture operations. Aquaculture Research 41, 777-792.

Crews, D.H., 2005. Genetics of efficient feed utilization and national cattle evaluation: a review. Genetics and Molecular Research 4, 152-165. 
Dupont-Prinet, A., Chatain, B., Grima, L., Vandeputte, M., Claireaux, G., McKenzie, D.J., 2010. Physiological mechanisms underlying a trade-off between growth rate and tolerance of feed deprivation in the European sea bass (Dicentrarchus labrax). The Journal of Experimental Biology 213, 1143-1152.

Emmerson, D.A., 1997. Commercial approaches to genetic selection for growth and feed conversion in domestic poultry. Poultry Science 76, 1121-1125.

Fauvel, C., Suquet, M., Dréanno C., Zonno V., Menu, B., 1998. Cryopreservation of seabass (Dicentrarchus labrax) spermatozoa in experimental and production simulating conditions. Aquatic Living Resources 11, 387-94.

Grima, L., Quillet, E., Boujard, T., Robert-Granie, C., Chatain, B., Mambrini, M., 2008. Genetic variability in residual feed intake in rainbow trout clones and testing of indirect selection criteria. Genetics Selection Evolution 40, 607-624.

Grima, L., Vandeputte , M. , Ruelle, F. , Vergnet, A., Mambrini, M., Chatain, B., 2010a. In search for indirect criteria to improve residual feed intake in sea bass (Dicentrarchus labrax) Part I: Phenotypic relationship between residual feed intake and body weight variations during feed deprivation and re-feeding periods. Aquaculture 300, 50-58.

Grima, L., Chatain, B., Ruelle, F., Vergnet, A., Launay, A., Mambrini, M., Vandeputte, M., 2010b. In search for indirect criteria to improve residual feed intake in sea bass (Dicentrarchus labrax) Part II: Heritability of weight loss during feed deprivation and weight gain during re-feeding periods. Aquaculture 302, 169-174.

Grima, L. Vers une amélioration de l'efficacité alimentaire chez le poisson : nouveaux critères et voie de sélection. [en ligne]. Thèse Sciences de la vie et de la santé. AgroParisTech, 2010. http://archimer.ifremer.fr/doc/00024/13550/10590.pdf

Haffray, P., Pincent, C., Dupont-Nivet, M., Vandeputte, M., Merdy, O., Chavanne, H., Chatain, B., 2007. Heritabilities and $\mathrm{G} \times \mathrm{E}$ interactions for quality traits in the European sea bass (Dicentrarchus labrax L.). Aquaculture 272S1, S238-S321.

Handeland, S.O., Imsland, A.K., Stefansson, S.O., 2008. The effect of temperature and fish size on growth, feed intake, food conversion efficiency and stomach evacuation rate of Atlantic salmon post-smolts. Aquaculture 283, 36-42.

Helland, S.J., Grisdale-Helland, B., Nerland, S., 1996. A simple method for the measurement of daily feed intake of groups of fish in tanks. Aquaculture 139 157-163.

Imsland, A.K., Fosst, A., Sparboes, L.O., Sigurdsson, S., 2006. The effect of temperature and fish size on growth and feed efficiency ratio of juvenile spotted wolffish (Anarhichas minor). Journal of Fish Biology 68, 1107-1122.

Iwama, G.K., Tautz, A.F., 1981. A Simple Growth Model for Salmonids in Hatcheries. Canadian Journal of Fisheries and Aquatic Science 38, 649-656.

Kause, A., Tobin, D., Dobly, A., Houlihan, D., Martin, S., Mänsiaari, E.A., Ritola, O., Ruohonen, K., 2006. Recording strategies and selection potential of feed intake measured using the X-ray method in rainbow trout. Genetics Selection Evolution38, 389-409.

Kinghorn, B., 1983. Genetic variation in food conversion efficiency and growth in rainbow trout. Aquaculture 32, 141-155.

Kolstad, K., Grisdale-Helland, B., Gjerde, B., 2004. Family differences in feed efficiency in Atlantic salmon (Salmo salar). Aquaculture 241, 169-177.

Luiting, P., 1999. The role of genetic variation in feed intake and its physiological aspects: results from selection experiment. In: editor(s)?? Regulation of feed intake. CABI Publishing, Wallingford. Pp. 75-87.

Mambrini, M., Sanchez, M.P., Chevassus, B., Labbé, L., Quillet, E., Boujard, T., 2004. Selection for growth increases feed intake and affects feeding behavior of brown trout. Livestock Production Science 88, 85-98. 
Martins, C.I.M., Schrama, J.W, Verreth, J.A.J, 2006. The relationship between individual differences in feed efficiency and stress response in African catfish Clarias gariepinus. Aquaculture 256, 588-595.

Martins, C.I.M., Hillen, B., Schrama, J.W., Verreth, J.A.J, 2008 A brief note on the relationship between residual feed intake and aggression behaviour in juveniles of African catfish Clarias gariepinus. Applied Animal Behavior Science 111, 408-413.

Mas-Muñoz, J., Komen, H., Schneider, O., Visch, S.W., Schrama, J.W., 2011. Feeding behaviour, swimming activity and boldness explain variation in feed intake and growth of sole (Solea solea) reared in captivity. PLoS ONE 6(6): e21393. doi:10.1371/journal.pone.0021393.

Mattila, J., Koskela, J., Pirhonen, J., 2009. The effect of the length of repeated feed deprivation between single meals on compensatory growth of pikeperch Sander lucioperca. Aquaculture 296, 65-70.

Millot, S. Variabilité des aptitudes comportementales et de la tolérance au stress de groupes génétiquement distincts de bar, Dicentrarchus labrax. [en ligne]. Thèse Océanologie Biologique et Environnement Marin. La Rochelle, 2008. http://archimer.ifremer.fr/doc/2008/these-6272.pdf

Neely, K.G., Myers, J.M., Hard, J.J., Shearer, K.D., 2008. Comparison of growth, feed intake, and nutrient efficiency in a selected strain of coho salmon (Oncorhynchus kisutch) and its source stock. Aquaculture 283, 134-140.

Nicholas, F.W., 1980. Size of population required for artificial selection. Genetical Research 35, 85105.

Nikki, J., Pirhonen, J., Jobling, M., Karjalainen, J., 2004.Compensatory growth in juvenile rainbow trout, Oncorhynchus mykiss (Walbaum), held individually. Aquaculture 235, 285-296.

Ogata, H.Y., Oku, H., Murai, T., 2002. Growth performance and macronutrient retention of offspring from wild and selected red sea bream (Pagrus major). Aquaculture 206, 279-287.

Oh, S.Y., Noh, C.H., 2007. Effect of restricted feeding regimes on compensatory growth and body composition of red sea bream, Pagrus major. Journal of the World Aquaculture Society 3, 443449.

Quillet, Q., Le Guillou, S., Aubin, J., Labbé, L., Fauconneau, B., Médale, F., 2007. Response of a lean muscle and a fat muscle rainbow trout (Oncorhynchus mykiss) line on growth, nutrient utilization, body composition and carcass traits when fed two different diets. Aquaculture 269, 220-231.

Quinton, C.D., Kause, A., Ruohonen, K., Koskela, J., 2007. Genetic relationships of body composition and feed utilization traits in European whitefish (Coregonus lavaretus L.) and implications for selective breeding in fish meal and soybean meal-based diet environments. Journal of Animal Science 85, 3198-3208.

Sanchez, M.P., Chevassus, B., Labbé, L., Quillet, E., Mambrini, M., 2001. Selection for growth of brown trout (Salmo trutta) affects feed intake but not feed efficiency. Aquatic Living Resources $14,41-48$.

Silverstein, J.T., 2006. Relationships among feed intake, feed efficiency, and growth in juvenile rainbow trout. North American Journal of Aquaculture 68, 168-175.

Tacon, G.H., Metian, M., 2008.Global overview on the use of fish meal and fish oil in industrially compounded aquafeeds: Trends and future prospects. Aquaculture 285, 146-158.

Talbot., C., Higgins, P.J., 1983. A radiographic method for feeding studies on fish using metallic iron powder as a marker. Journal of Fish Biology 23, 211-220.

Talbot, C., Hole, R.,1994. Fish diets and the control of eutrophication resulting from aquaculture. Journal of Applied Ichthyology 10, 258-270.

Thodesen, J., Grisdale-Helland, B., Helland, S.J., Gjerde, B., 1999. Feed intake, growth and feed utilization of offspring from wild and selected Atlantic salmon. Aquaculture 180, 237-246. 
Thodesen, J., Gjerde, B., Grisdale-Helland, B., Storebakken, T., 2001. Genetic variation in feed intake, growth and feed utilization in Atlantic salmon (Salmo salar). Aquaculture 194, 273281.

Vandeputte, M., Mauger, S., Dupont-Nivet ,M., 2006. An evaluation of allowing formismatches as a way to manage genotyping errors in parentage assignment by exclusion. Molecular Ecology Notes 6, 265-267.

Vandeputte, M., Dupont-Nivet, M., Chatain, B., Chevassus, B., 2001. Setting up a strain-testing design for the seabass, Dicentrarchus labrax: a simulation study. Aquaculture 202, 329-342.

Wang, N., Xu, X., Kestemont, P., 2009. Effect of temperature and feeding frequency on growth performances, feed efficiency and body composition of pikeperch juveniles (Sander lucioperca). Aquaculture 289, 70-73. 
Table 1. Mean body weight $(\mathrm{BW}) \pm \mathrm{SE}$ and mean condition coefficient $(\mathrm{K}) \pm \mathrm{SE}$ of $\mathrm{FD}^{+}$and $\mathrm{FD}^{-}$ lines measured during alternating feed deprivation and re-feeding periods. $P$-value for the line effect and $R^{2}$ were obtained with anova . $_{\text {. }}$

\begin{tabular}{cccccc}
\hline \multirow{2}{*}{ age } & trait & FD+ strain & FD- strain & $\boldsymbol{P}$ & $\mathbf{R}^{\mathbf{2}}$ \\
\cline { 2 - 6 } $227 \mathrm{dpf}$ & $\mathrm{BW}$ & $27.8 \pm 0.38$ & $28.8 \pm 0.44$ & 0.6818 & 0.26 \\
& $\mathrm{~K}$ & $1.12 \pm 0.004$ & $1.17 \pm 0.004$ & 0.2435 & 0.26 \\
\cline { 2 - 6 } $276 \mathrm{dpf}$ & $\mathrm{BW}$ & $37.9 \pm 0.52$ & $40.1 \pm 0.60$ & 0.5398 & 0.25 \\
& $\mathrm{~K}$ & $1.15 \pm 0.004$ & $1.20 \pm 0.004$ & 0.0389 & 0.27 \\
\cline { 2 - 6 } $297 \mathrm{dpf}$ & $\mathrm{BW}$ & $33.9 \pm 0.47$ & $36.3 \pm 0.54$ & 0.433 & 0.26 \\
& $\mathrm{~K}$ & $1.02 \pm 0.004$ & $1.07 \pm 0.04$ & 0.1058 & 0.21 \\
\cline { 2 - 6 } $324 \mathrm{dpf}$ & $\mathrm{BW}$ & $56.0 \pm 0.74$ & $60.0 \pm 0.84$ & 0.3956 & 0.25 \\
& $\mathrm{~K}$ & $1.17 \pm 0.004$ & $1.23 \pm 0.004$ & 0.0426 & 0.26 \\
\cline { 2 - 6 } $345 \mathrm{dpf}$ & $\mathrm{BW}$ & $50.2 \pm 0.67$ & $53.8 \pm 0.77$ & 0.4936 & 0.25 \\
& $\mathrm{~K}$ & $1.01 \pm 0.004$ & $1.06 \pm 0.004$ & 0.1107 & 0.21 \\
\cline { 2 - 6 } $366 \mathrm{dpf}$ & $\mathrm{BW}$ & $70.4 \pm 0.91$ & $76.2 \pm 1.03$ & 0.3994 & 0.25 \\
& $\mathrm{~K}$ & $1.19 \pm 0.003$ & $1.25 \pm 0.004$ & 0.0792 & 0.28 \\
\cline { 2 - 6 } $387 \mathrm{dpf}$ & $\mathrm{BW}$ & $63.6 \pm 0.85$ & $69.0 \pm 0.96$ & 0.3604 & 0.25 \\
& $\mathrm{~K}$ & $1.02 \pm 0.003$ & $1.07 \pm 0.003$ & 0.1316 & 0.33 \\
\hline \multirow{3}{*}{$408 \mathrm{dpf}$} & $\mathrm{BW}$ & $88.3 \pm 1.16$ & $96.3 \pm 1.32$ & 0.2952 & 0.26 \\
& $\mathrm{~K}$ & $1.20 \pm 0.004$ & $1.27 \pm 0.004$ & 0.0753 & 0.28 \\
\hline
\end{tabular}


Table 2. Mean TGC (Thermal Growth Coefficient) during BG (Basic Growth period), and the alternate of feed deprivation and re-feeding period measured on $\mathrm{FD}^{-}$and $\mathrm{FD}^{+}$lines. Mean $\mathrm{TGC}_{\mathrm{FD}}$ and mean $T G C_{R F}$ are respectively the means of the three periods of $F D$ and $R F$. ancova ${ }_{1}$ is corresponding to a model corrected by $\mathrm{BW}_{0}$ and $\mathrm{TGC}_{0}$, and ancova $\mathrm{a}_{2}$ is corresponding to a model with a correction by $\mathrm{TGC}_{0}$ only. NA: not applicable ; ND: not done due to heterogeneity of slopes between $\mathrm{FD}^{-}$and $\mathrm{FD}^{+}$groups.

\begin{tabular}{lccccc}
\hline Trait & FD+ strain & FD- strain & $\begin{array}{c}\text { ANCOVA1 } \\
P ; R^{2}\end{array}$ & $\begin{array}{c}\text { ANCOVA2 } \\
P ; R^{2}\end{array}$ & $\begin{array}{c}\text { ANOVA } \\
P ; R^{2}\end{array}$ \\
TGC0 & $0.033 \pm 0.00041$ & $0.037 \pm 0.00047$ & NA & NA & $0.20 ; 0.24$ \\
TGCf11 & $-0.030 \pm 0.00019$ & $-0.028 \pm 0.00022$ & $0.0001 ; 0.27$ & $0.0002 ; 0.24$ & $0.00 ; 0.16$ \\
TGCrf1 & $0.101 \pm 0.00056$ & $0.105 \pm 0.00064$ & $0.37 ; 0.39$ & $0.36 ; 0.35$ & $0.08 ; 0.18$ \\
TGCf2 & $-0.032 \pm 0.00022$ & $-0.031 \pm 0.00024$ & ND & $0.13 ; 0.18$ & $0.20 ; 0.16$ \\
TGCrf2 & $0.097 \pm 0.00051$ & $0.101 \pm 0.00059$ & ND & $0.12 ; 0.29$ & $0.03 ; 0.19$ \\
TGCfd3 & $-0.034 \pm 0.00023$ & $-0.032 \pm 0.00026$ & $0.02 ; 0.18$ & $0.02 ; 0.17$ & $0.02 ; 0.19$ \\
TGCrf3 & $0.100 \pm 0.00065$ & $0.104 \pm 0.00074$ & $0.11 ; 0.32$ & $0.13 ; 0.25$ & $0.07 ; 0.16$ \\
mean TGCfd & $-0.032 \pm 0.00016$ & $-0.030 \pm 0.00019$ & ND & $0.008 ; 0.26$ & $0.03 ; 0.17$ \\
mean TGCrf & $0.100 \pm 0.00049$ & $0.104 \pm 0.00055$ & $0.06 ; 0.44$ & $0.07 ; 0.37$ & $0.01 ; 0.21$ \\
\hline
\end{tabular}

Table 3. Means \pm SE of body weight $(B W)$, condition factor $(K)$, Fat content $(F c)$, hepatosomatic index $(\mathrm{HSI})$, digestive tract index (DTI), visceral fat index (VFI), and carcass yield (carc. $\mathrm{Y}$ ), in $\mathrm{FD}^{+}$ and $\mathrm{FD}^{-}$line during four periods of feed efficiency measurement. $P$ and $R^{2}$ are values obtained performing anova . $_{\text {. }}$

\begin{tabular}{cccccc}
\hline age & trait & FD+ line & FD- line & $\boldsymbol{P}$ & $\mathbf{R}^{\mathbf{2}}$ \\
\cline { 2 - 6 } $428 \mathrm{dpf}$ & $\mathrm{BW}$ & $109.5 \pm 1.7$ & $117.8 \pm 1.7$ & 0.0008 & 0.03 \\
& $\mathrm{~K}$ & $1.27 \pm 0.00$ & $1.33 \pm 0.00$ & $<.0001$ & 0.14 \\
& $\mathrm{FC}$ & $3.7 \pm 0.1$ & $4.5 \pm 0.1$ & $<.0001$ & 0.08 \\
\cline { 2 - 6 } $448 \mathrm{dpf}$ & $\mathrm{BW}$ & $105.0 \pm 1.4$ & $115.3 \pm 1.4$ & 0.0002 & 0.04 \\
& $\mathrm{~K}$ & $1.11 \pm 0.01$ & $1.17 \pm 0.01$ & $<.0001$ & 0.18 \\
& $\mathrm{FC}$ & $2.7 \pm 0.2$ & $3.5 \pm 0.2$ & 0.0076 & 0.12 \\
\cline { 2 - 6 } $469 \mathrm{dpf}$ & $\mathrm{BW}$ & $117.7 \pm 3.1$ & $132.6 \pm 3.1$ & 0.0041 & 0.08 \\
& $\mathrm{~K}$ & $1.12 \pm 0.01$ & $1.21 \pm 0.01$ & $<.0001$ & 0.25 \\
& $\mathrm{FC}$ & $2.9 \pm 0.1$ & $3.9 \pm 0.1$ & $<.0001$ & 0.10 \\
\cline { 2 - 6 } $490 \mathrm{dpf}$ & $\mathrm{BW}$ & $139.1 \pm 3.1$ & $160.2 \pm 3.1$ & 0.0003 & 0.08 \\
& $\mathrm{~K}$ & $1.18 \pm 0.01$ & $1.26 \pm 0.01$ & $<.0001$ & 0.25 \\
& $\mathrm{FC}$ & $3.3 \pm 0.1$ & $4.4 \pm 0.1$ & $<0.001$ & 0.26 \\
\cline { 2 - 6 } & $\mathrm{BW}$ & $161.9 \pm 3.6$ & $187.8 \pm 3.6$ & 0.0001 & 0.09 \\
& $\mathrm{~K}$ & $1.18 \pm 0.01$ & $1.26 \pm 0.01$ & 0.0001 & 0.22 \\
$511 \mathrm{dpf}$ & $\mathrm{FC}$ & $4.1 \pm 0.20$ & $5.1 \pm 0.10$ & 0.0032 & 0.13 \\
& $\mathrm{HSI}$ & $1.80 \pm 0.04$ & $1.87 \pm 0.04$ & 0.1446 & 0.13 \\
& $\mathrm{DTI}$ & $2.22 \pm 0.04$ & $2.19 \pm 0.04$ & 0.5348 & 0.10 \\
& $\mathrm{VFI}$ & $6.90 \pm 0.23$ & $8.66 \pm 0.22$ & 0.0004 & 0.38 \\
& Carc.Y & $86.8 \pm 0.2$ & $85.2 \pm 0.2$ & 0.0005 & 0.30 \\
\hline
\end{tabular}


Figure 1: Mean body weight (BW) and mean thermal growth coefficient (TGC) evolution of $\mathrm{FD}^{+}$and FD- lines. Body growth $(B G)$ corresponds to a growing period, $F_{1}, F_{2}, F_{3}$ respectively correspond to the first, the second, and the third period of feed deprivation, and $\mathrm{RF}_{1}, \mathrm{RF}_{2}, \mathrm{RF}_{3}$ respectively correspond to the first, the second, and the third period of re-feeding. $\Delta$ : mean $B W \pm S E(g)$ of FD- line ; $\triangle$ : mean BW \pm SE (g) of $\mathrm{FD}^{+}$line ; $\bullet$ mean TGC of FD- line ; $\diamond:$ mean TGC of $\mathrm{FD}^{+}$ line.

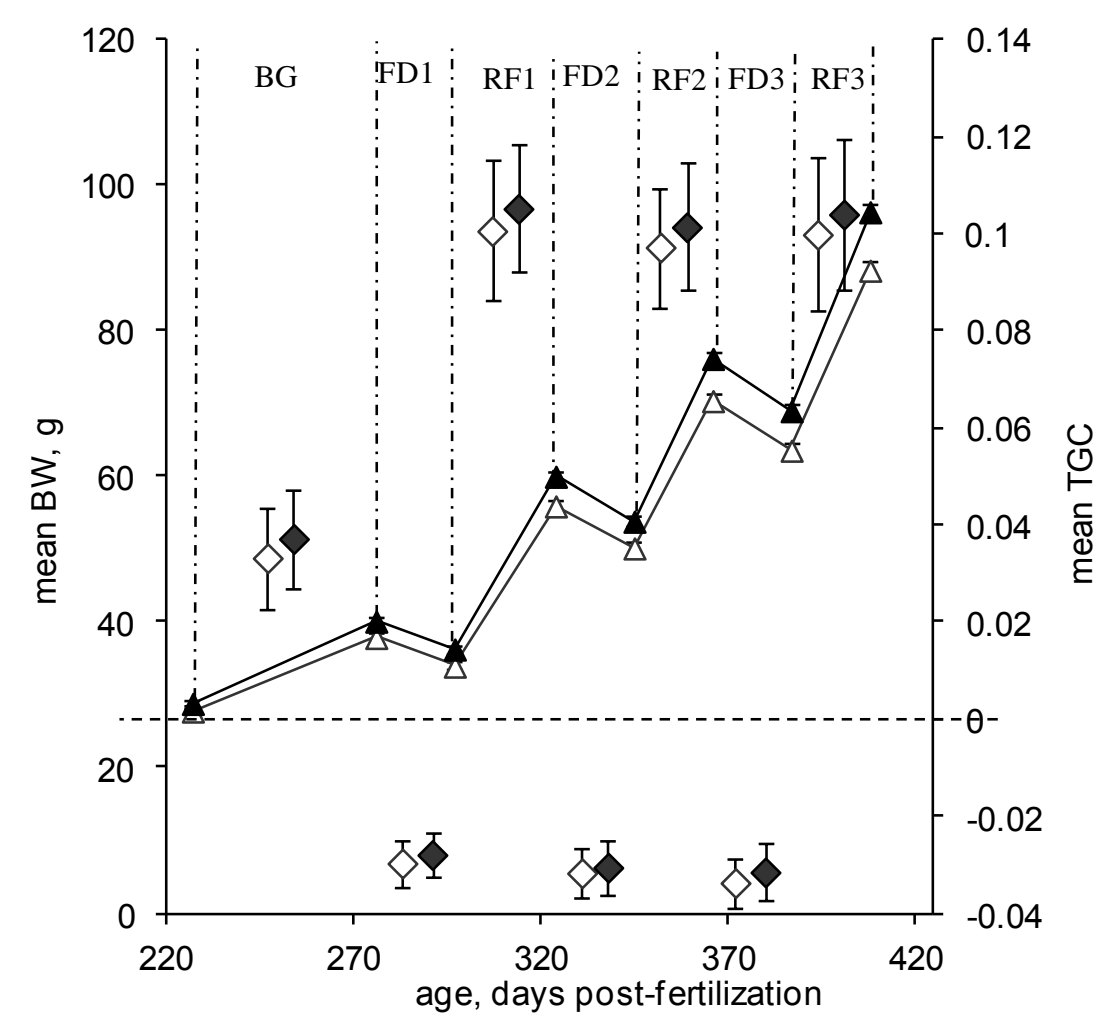


Figure 2: Mean feed intake (MFI), thermal growth coeffiecient (TGC), feed efficiency ratio (FER), and residual feed intake (RFI) measured during $F E M_{1}, F E M_{2}, F E M_{3}$, and $F E M_{4}$. Values are given for $\mathrm{FD}^{+}$line in light grey, and for FD- line in dark grey. F-test were performed with anova ${ }_{2}$ for FER, $\mathrm{MFI}$, and RFI, and with anova ${ }_{3}$ for TGC.

$P<0.05 ;{ }^{* *}: P<0.01 ;{ }^{* \star *}: P<0.001$
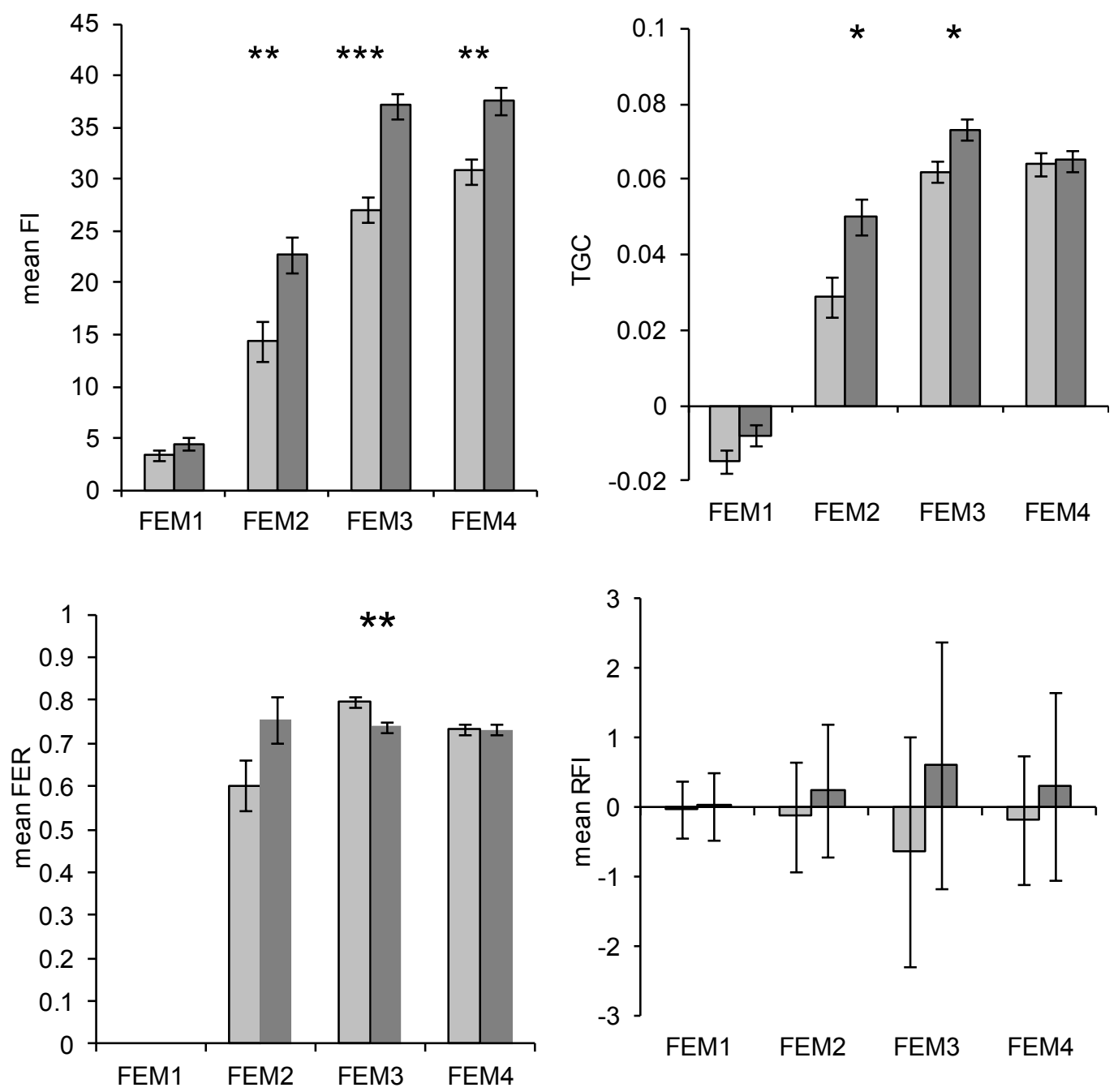